\title{
Porcine model elucidates function of p53 isoform in carcinogenesis and reveals novel circTP53 RNA
}

\author{
Guanglin Niu ${ }^{1}$ - Isabel Hellmuth ${ }^{1} \cdot$ Tatiana Flisikowska $^{1} \cdot$ Hubert Pausch $^{2} \cdot$ Beate Rieblinger $^{1}$. \\ Alexander Carrapeiro ${ }^{1} \cdot$ Benjamin Schade $^{3} \cdot$ Brigitte Böhm $^{3} \cdot$ Eva Kappe $^{3} \cdot$ Konrad Fischer $^{1} \cdot$ Bernhard Klinger $^{1}$. \\ Katja Steiger $\mathbb{D}^{4} \cdot$ Reiner Burgkart ${ }^{5} \cdot$ Jean-Christophe Bourdon $\mathbb{D}^{6} \cdot$ Dieter Saur $\mathbb{D}^{7} \cdot$ Alexander Kind ${ }^{1}$. \\ Angelika Schnieke $\mathbb{i}^{1} \cdot$ Krzysztof Flisikowski $\mathbb{B}^{1}$
}

Received: 25 September 2020 / Revised: 19 January 2021 / Accepted: 27 January 2021

(c) The Author(s) 2021. This article is published with open access

\begin{abstract}
Recent years have seen an increasing number of genetically engineered pig models of human diseases including cancer. We previously generated pigs with a modified TP53 allele that carries a Cre-removable transcriptional stop signal in intron 1, and an oncogenic mutation $T P 53^{R 167 H}$ (orthologous to human $T P 53^{R 175 H}$ ) in exon 5. Pigs with the unrecombined mutant allele (flTP53 ${ }^{R 167 H}$ ) develop mainly osteosarcoma but also nephroblastomas and lymphomas. This observation suggested that TP53 gene dysfunction is itself the key initiator of bone tumorigenesis, but raises the question which aspects of the TP53 regulation lead to the development of such a narrow tumour spectrum. Molecular analysis of p53 revealed the presence of two internal TP53 promoters (Pint and P2) equivalent to those found in human. Consequently, both pig and human express TP53 isoforms. Data presented here strongly suggest that P2-driven expression of the mutant R167H- $\Delta 152 \mathrm{p} 53$ isoform (equivalent to the human R175H- $\Delta 160 \mathrm{p} 53$ isoform) and its circular counterpart circTP53 determine the tumour spectrum and play a critical role in the malignant transformation in fITP5 $3^{R 167 H}$ pigs. The detection of $\Delta 152 \mathrm{p} 53$ isoform mRNA in serum is indicative of tumorigenesis. Furthermore, we showed a tissue-specific p53-dependent deregulation of the p63 and p73 isoforms in these tumours. This study highlights important species-specific differences in the transcriptional regulation of TP53. Considering the similarities of TP53 regulation between pig and human, these observations provide useful pointers for further investigation into isoform function including the novel circTP53 in both the pig model and human patients.
\end{abstract}

Supplementary information The online version contains supplementary material available at https://doi.org/10.1038/s41388021-01686-9.

Krzysztof Flisikowski

flisikowski@wzw.tum.de

1 Chair of Livestock Biotechnology, Technische Universität München, Munich, Germany

2 Animal Genomics, ETH Zurich, Zurich, Switzerland

3 Department of Pathology, Bavarian Animal Health Service, Poing, Germany

4 School of Medicine, Institute of Pathology, Technische Universität München, Munich, Germany

5 Klinik und Poliklinik für Orthopädie und Sportorthopädie, Klinikum rechts der Isar, Technische Universität München, Munich, Germany

6 Jacqui Wood Cancer Centre, School of Medicine, University of Dundee, Dundee, UK

7 Department of Internal Medicine II, Klinikum rechts der Isar, Technische Universität München, Munich, Germany

\section{Introduction}

In human, osteosarcomas (OS) is the major form of primary bone cancer [1]. It predominantly affects young people and is highly malignant, requiring aggressive surgical resection and cytotoxic chemotherapy [2]. The 5-year survival rate has remained unchanged over the past 20 years, at $\sim 60 \%$ for patients with primary osteosarcoma and $\sim 20 \%$ for patients with metastatic disease [3]. Most OS are sporadic and of unknown cause, but increased incidence is associated with Li-Fraumeni syndrome caused by germ line mutation of TP53 $[4,5]$.

The role of TP53 mutations in numerous cancers has been extensively documented [6]. Yet, potentially important aspects of TP53 gene function still remain unclear, including the role of various p53 isoforms. Human TP53 is known to express at least 9 different mRNA transcripts [7] and at least 12 protein isoforms [8], with transcription initiated by two promoters: P1 at the 5' end and P2 in intron 4; alternative splicing across introns 2 and 9; and alternative translation initiated at internal 
start codons 40, 133 and 160 . The internal promoter P2 originates the $\Delta 133 \mathrm{p} 53$ and $\Delta 160 \mathrm{p} 53$ isoforms in humans. While the function of $\Delta 160 \mathrm{p} 53$ is less studied, the $\Delta 133 \mathrm{p} 53$ is involved in the regulation of replicative cellular senescence [9], angiogenesis, cytokine secretion/immune response and tumour progression in some cancer types [10].

Pigs have become an important animal model for human cancers research, translational studies and preclinical trials $[11,12]$. We have generated genetically engineered (GE) pigs with mutations in key tumour suppressor genes and protooncogenes [13] to facilitate preclinical studies [14]. As part of this programme we generated pigs modelled on GE mice carrying a Cre-inducible oncogenic mutant $\operatorname{Trp} 53^{R I 72 H}$ allele, in which a floxed transcriptional stop cassette is inserted into Trp53 intron 1 to block transcription of the mutated allele [15]. The latent allele can be experimentally activated by Cre recombinase to express mutant $\mathrm{p} 53^{\mathrm{R} 172 \mathrm{H}}$ and model spontaneous somatic Trp53 mutation in chosen organs. These mice have been used successfully to model a series of cancers, e.g., pancreatic, breast and lung [16-19]. Similarly, our pig line carries an engineered endogenous TP53 gene with a floxed transcriptional stop signal in intron 1 and a point mutation resulting in an arginine to histidine substitution at codon 167 in exon $5\left(T P 53^{R 167 H}\right.$, orthologous to mouse $\operatorname{Tr} p 53^{R 172 H}$ and human $T P 53^{R 175 H}$ ) [20]. As this pig line was being established it became apparent that animals with the latent non-induced allele (designated here as flTP53 $3^{R 167 H}$ ) in both heterozygous and homozygous form developed OS [21] and less frequently kidney tumours and lymphomas.

This phenotype contrasts sharply with that reported for mice carrying the apparently equivalent non-induced $\operatorname{Trp} 53^{R 172 H}$ allele, which mostly develop lymphoma [22]. None of the murine Trp53 mutant strains so far generated show a preponderance of OS in the tumour spectrum [22, 23]. These include Cre-inducible point mutations [23], partial deletions of the Trp53 coding region [15] and transgenic lines that overexpress mutant $\operatorname{Trp} 53^{R 270 H}$ and $\operatorname{Trp} 53^{R 172 H}$ from exogenous promoters [24]. To increase the incidence of OS, several mouse strains expressing osteoblast- and mesenchymal-specific Cre coupled with conditional $p 53$ and $R b 1$ mutant alleles were generated [25].

These findings indicate a species-specific difference in p53 gene regulation. Differences in the p53 isoforms and internal promoters have been described for humans, primates, zebrafish, drosophila and mouse [8]. Here we show that unlike the mouse, the porcine TP53 locus contains internal Pint and P2 promoters equivalent to those found in human, resulting in expression of $\Delta 152 \mathrm{p} 53 \alpha$ isoform and its circular counterpart circTP53. Both are involved in the development of OS and others tumours in the flTP53 $3^{R I 67 H}$ pigs and the detection of $\Delta 152 \mathrm{p} 53 \alpha$ isoform in serum is indicative of tumorigenesis. A tissue-specific p53-dependent deregulation of p63 and p73 isoforms could be observed in these tumours.

\section{Results}

\section{Cancer spectrum in flTP53 ${ }^{\mathrm{R} 167 \mathrm{H}}$ pigs}

Since our publication describing the generation of flTP53 ${ }^{R 167 H}$ pigs [20], a total of $29 \mathrm{flTP} 53^{\text {R167H/+ }}$ heterozygous and $10 \mathrm{flTP} 53^{R 167 H / R 167 H}$ homozygous pigs were examined by necropsy. All had reached sexual maturity. Animals were sacrificed as soon as they showed symptoms effecting their wellbeing or in case of the heterozygous animals latest at the age of 36 months. By this time 18 of the 29 heterozygous animals had developed tumours, all of which were classified histologically as osteoblastic OS. Spontaneous OS is very rare in wild-type pigs [21, 26]. All homozygous pigs had OS by the age of 16 months or earlier and five of these (aged 7-14 months) also had nephroblastoma (kidney) and diffuse large B-cell lymphomas (spleen). In each case the anatomical location and histological analyses of the tumours resembled those of the human juvenile cancer.

\section{Identification of a $\Delta 152 \mathrm{p} 53 a$ isoform in pigs}

The observation that the tumour repertoire was restricted to a few tissue types (100\% OS, 22\% nephroblastoma and $17 \%$ B-cell lymphomas) leads to the question which aspects of TP53 expression or absence thereof support the formation of mainly OS rather than other tumour entities? To answer this question, we first establish if expression of the floxed fITP5 $3^{R 167 H}$ allele was silenced in all organs.

A series of RT-PCR primers hybridising to different porcine TP53 exons (Fig. 1a) were used to screen RNA samples from various organs $(n=11)$ of flTP53 $3^{R 167 H / R 167 H}$ homozygous pigs $(n=3)$. No mRNA expression was detected using RT-PCR primers specific for exon 1 to exon $2(1 \mathrm{~F} / 1 \mathrm{R})$, or exon 2 to $4(2 \mathrm{~F} / 2 \mathrm{R})$ in all tissues analysed including bone and OS samples (Fig. 1b), confirming that the LSL efficiently blocked transcription. However, RT-PCR using primers between exons 5 and 11 (5F/9R, see Fig. 1a) revealed a tissuespecific expression (Fig. 1c), where the strongest RT-PCR signal was obtained for bone, lymph node and kidney tissues. This indicated the presence of a promoter element in intron 4 similar to human. No expression of the short TP53 mRNA was detected in heart and aorta. To determine the start and termination of the porcine TP53 isoform 5' and 3' rapid amplification of cDNA end (RACE) analysis was performed (Fig. 1d, e). This placed the start of the isoform 11 base pairs upstream of exon 5 with a possible ATG at amino acid position $152(\Delta 152 \mathrm{p} 53$ isoform), which translates in frame and terminates at the same stop codon as the full length p53 and corresponds to TP53 $\alpha$ isoform (Supplementary Fig. 1). The identified $\Delta 152 \mathrm{p} 53 \alpha \mathrm{mRNA}$ has a length of $1295 \mathrm{bp}$; the nucleotide sequence was verified by sequencing. 


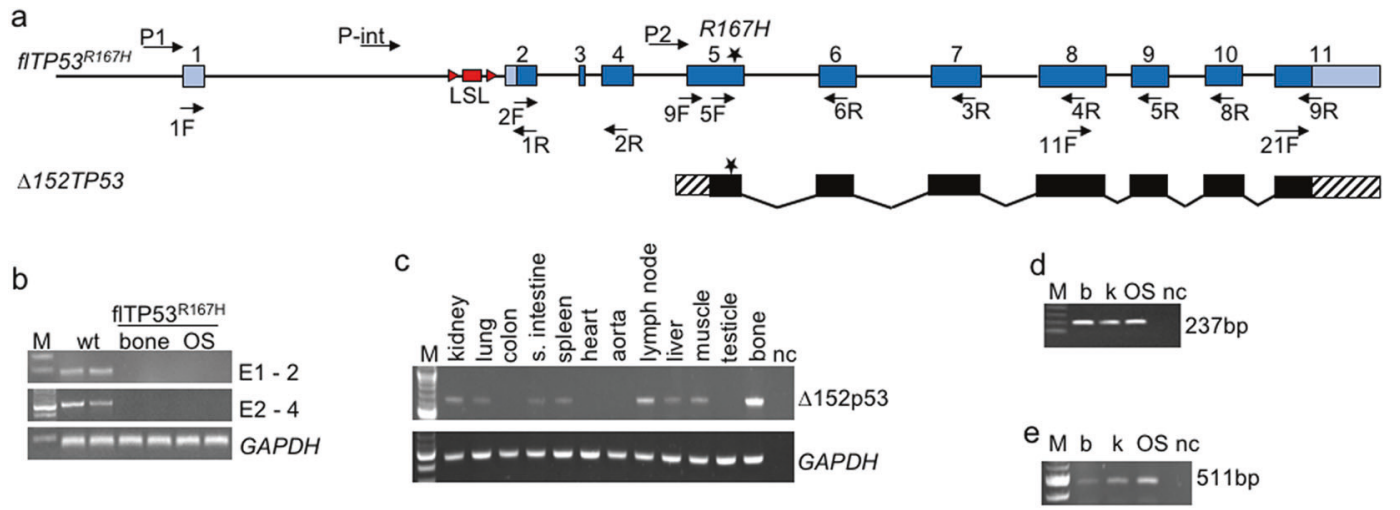

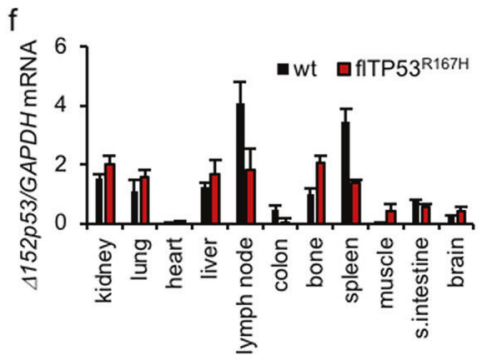

Fig. 1 Identification of $\Delta \mathbf{1 5 2 p 5 3 \alpha}$ isoform in pigs. a Schematic representation of the TP53 gene and the $\Delta 152 \mathrm{p} 53 \alpha$ mRNA. b Expression analysis across exon 1 to 2 (186 bp), exon 2 to 4 (591 bp) of bone samples from wild-type pigs and healthy bone and OS samples from $A T P 53^{R 167 H / R 167 H}$ pigs showing lack of expression for mutant TP53. c Expression analysis across exon 5 to 11 (492 bp) for 11 different organ samples from $f T P 53^{R 167 H / R 167 H}$ pigs. d 5' RACE using a reverse primer hybridising to exon 6 of TP53 and resulting in a 237 bp fragment and e 3' RACE using forward primer hybridising to

\section{Expression of $\Delta 152 \mathrm{p} 53 \mathrm{a}$ isoform is highest in organs susceptible to cancer development}

By using primers $(9 \mathrm{~F} / 6 \mathrm{R})$ specific for the $\Delta 152 \mathrm{p} 53 \alpha$ isoform its expression was quantified by qPCR in different healthy tissues $(n=11)$ from flTP5 $3^{R 167 H}$ homozygous $(n=10)$ and wild-type $(n=3)$ pigs. The highest $\Delta 152 \mathrm{p} 53 \alpha$ mRNA expression in flTP53 ${ }^{R 167 H}$ homozygous pigs was observed in lymph nodes, spleen, kidney and bone (Fig. 1f), all organs prone to tumour development in mutant pigs. Except for lymph node, colon and small intestine the $\triangle 152 \mathrm{p} 53 \alpha$ mRNA expression was generally lower in wildtype samples, than in flTP5 $3^{R I 67 H}$ homozygous samples.

\section{The porcine $\Delta 152 \mathrm{p} 53 a$ isoform encodes a $30 \mathrm{kDa}$ protein}

The methionine codon 152 in pigs corresponds to codon 160 in human $\mathrm{p} 53$, which is located within a highly conserved Kozak sequence [27]. An in silico analysis predicted that the 1295 bp mRNA encodes a 224 amino acid N-terminaltruncated $\Delta 152 \mathrm{p} 53 \alpha$ isoform using the same reading frame as full length $\mathrm{p} 53$. The predicted porcine isoform shares $88 \%$ exon 11 of TP53 resulting in a 511 bp fragment. Healthy bone (b), kidney (k) and osteosarcoma (OS) samples from $A T P 53^{R 167 H / R 167 H}$ pigs. $\mathrm{M}$ marker, nc negative control. $\mathbf{f}$ Quantitative RT-PCR analysis using primers hybridising to extended exon 5 and exon 6 and detecting the $\Delta 152 \mathrm{p} 53$ isoform mRNA expression in different tissues of $f T P 5^{R 167 H / R 167 H}(n=6)$ and wild-type $(n=3)$ pigs. $G A P D H$ was used as a reference gene to calculate the relative expression levels. $\mathrm{g}$ Detection of $\Delta 152 \mathrm{p} 53$ isoform by western blot analysis using SAPU antibody in different tissues from $f T P 5^{R I 67 H / R 167 H}$ pigs.

amino acid sequence homology with the human $\Delta 160 \mathrm{p} 53 \alpha$ isoform, which uses the $\Delta 133 / 160 \mathrm{p} 53$ alternative transcriptional initiation site in exon 5 [27] and contains part of the highly conserved p53 DNA binding region [8]. To determine whether the porcine TP53 alternative transcript can produce $\triangle 152 \mathrm{p} 53 \alpha$ protein, western blot analysis of different healthy tissue samples from fiTP53 $3^{R 167 H / R 167 H}$ homozygous pigs was performed using the polyclonal sheep SAPU antibody recognising all human p53 isoforms. Two bands (doublet) of $\sim 30 \mathrm{kD}$ were detected (Fig. 1g). As with the mRNA highest protein expression was observed in bone, kidney, lymph node and spleen. The size of the western blot bands was comparable to the human $\Delta 160 \mathrm{p} 53$ isoforms [27], and most likely represent splice variant or post-translational modifications of R167H- $\Delta 152 \mathrm{p} 53$ proteins.

\section{Identification of internal promoters in the porcine TP53}

Results above clearly indicated the presence of at least one internal promoter. To determine the location of all possible internal promoters, nucleotide sequence alignment was carried out between the porcine (NC_010454, GenBank Sscrofa 11.1) 
and human (NC_000017, Genbank GRCh38.p12) TP53 gene. Apart of exons, three genomic regions with high homology ( $>70 \%$ similarity) were detected $(-1877$ to $+11 \mathrm{bp},+2125$ to $+3200 \mathrm{bp}$ and +9985 to $+10,470 \mathrm{bp}$; relative to the major transcription start site). These porcine TP53 regions correspond to the locations of the P1 (5'end), Pint (intron 1) and P2 (intron 4) promoters in human TP53. As for the human sequence, the porcine intron 4 sequence (P2) contains binding sites for the transcription factors NFIC, Hltf and SPI1. In contrast, the sequence of mouse Trp53 intron 4 showed less than 50\% homology to human TP53, and lacks binding sites for these transcription factors (Supplementary Fig. 2). Interestingly, the NFIC transcription factor regulates osteoblast differentiation [28], and can promote or suppress the development of various cancers [29] via epigenetic changes [30]. The SPI1 transcription factor regulates alternative transcription of target genes, and both Hltf and SPI1 are frequently mutated in paediatric cancers $[31,32]$.

To confirm promoter function five luciferase reporter constructs were generated containing the P1 promoter ( $-2000 \mathrm{bp}$ to TSS), the putative P2 promoter (intron 4) and three different fragments covering the first intron (Pint_1, Pint_2, Pint_3), see Fig. 2a. Luciferase expression driven by the SV40 promoter was used as positive control.

Luciferase activity was measured after transfection of various porcine primary cells: wild-type bone marrow mesenchymal stem cells (bmMSC) and kidney fibroblasts; flTP53 ${ }^{R 167 H /}$ ${ }_{R 167 H}$ OS cells and healthy osteoblasts; and human HEK293 cells. In comparison to the positive control two of the putative promoter fragments led to moderate (P1, 40-70\% and Pint_1, $30-45 \%)$ and one to low (P2, 10-25\%) luciferase activity (Fig. 2a). These three promoter fragments shared the greatest homology with the corresponding human TP53 sequence. The in silico and experimental data provide evidence for the presence of internal promoters within intron 1 (Pint) and intron 4 (P2) of the porcine TP53, similar to those in human TP53.

Expression from the $\mathrm{P} 1$ and Pint promoters is blocked by lox-stop-lox cassette in $A T P 53^{R 167 H}$ homozygous pigs. Additional deletion of the $\mathrm{P} 2$ promoter fragment should result in a complete inactivation of porcine TP53. Using the Crispr-Cas9 system and two guide RNAs a DNA fragment from 9665 to 10,374 bp of pig TP53 (NC_010454) was excised in OS cells from $f T P 53^{R 167 H}$ homozygous pigs (Supplementary Fig. 3a). RT-PCR analysis showed no TP53 expression in the edited porcine OS cells (Supplementary Fig. 3b), confirming that the $\mathrm{P} 2$ promoter is responsible for the $\Delta 152 \mathrm{p} 53 \alpha$ expression.

\section{The $\mathrm{R} 167 \mathrm{H}-\Delta 152 \mathrm{p} 53 a$ isoform is overexpressed in tumours}

To assess the RNA and protein expression of $\Delta 152 \mathrm{p} 53 \alpha$ isoform in cancer, we analysed tumours collected from flTP53 ${ }^{R 167 H}$ pigs. Quantitative PCR and western blot revealed more than three-fold $(P<0.001)$ higher expression of R167H$\Delta 152 \mathrm{p} 53 \alpha$ isoform in OS compared to matched healthy bones (Fig. 2b-d). The level of $\Delta 152 \mathrm{p} 53 \alpha$ mRNA expression increased $\left(P=1.17 \times 10^{-5}\right)$ with OS tumour size (Fig. 2e).

The expression level of the $\Delta 152 \mathrm{p} 53 \alpha$ mRNA in healthy bones correlated with the onset of cancer clinical symptoms in homozygous flTP53 $3^{R 167 H}$ pigs (Fig. 2f). The higher $\mathrm{R} 167 \mathrm{H}-\Delta 152 \mathrm{p} 53 \alpha$ was expressed the earlier tumours became evident. In wild-type pigs the level of $\Delta 152 \mathrm{p} 53 \alpha$ expression remained unchanged with age (Fig. 2f).

The above results hinted that overexpression of the mutant $\mathrm{R} 167 \mathrm{H}-\Delta 152 \mathrm{p} 53 \alpha$ isoform was essential for tumorigenesis. To assess if this also applied to other tumour types samples from the nephroblastomas and B-cell lymphomas were analysed. As for the OS, an overexpression of $\Delta 152 \mathrm{p} 53 \alpha$ isoform was observed in kidney and spleen tumours (Fig. 2g). Finally, we also tested if the orthologous $\Delta 133 / 160$ p53 mRNA was expressed in human OS samples. These too were positive (Supplementary Fig. 4).

Overexpression of the $\Delta 152 \mathrm{p} 53 \alpha$ isoform seemed essential for tumour growth. To confirm this, and to assess if the effect was due to the expression of the wild-type or mutant isoform, a proliferation assay was performed. Pig OS cells transfected with an expression vector carrying the wild-type $\Delta 152 \mathrm{p} 53 \alpha$ or mutant R167H $\Delta 152 \mathrm{p} 53 \alpha$ cDNA sequence under the control of the CAG promoter showed significantly increased proliferation compared to those transfected with control GFP vector (Supplementary Fig. 5). The highest proliferative increase was obtained for the mutant isoform. Next, we tested if expression of the mutant $\mathrm{R} 167 \mathrm{H} \Delta 152 \mathrm{p} 53 \alpha$ isoform also increases cell migration and invasion. Compared to the control a significant difference was observed (Fig. 2i).

The MDM2 oncoprotein is a key regulator of p53 expression, which is stabilised by mutant p53 [33]. To determine if the mutant $\Delta 152 \mathrm{p} 53 \alpha$ protein isoform retains this function, western blot analysis was carried out and showed an increased MDM2 protein expression in OS tumour samples (Fig. 2c). Taken together, these data indicate that the mutant $\Delta 152 \mathrm{p} 53 \alpha$ isoform plays a critical role in the malignant transformation of bones, kidney or spleen in $\mathrm{flTP} 53^{R 167 H}$ pigs.

\section{Blood exosomal $\Delta 152 \mathrm{p} 53 a$ expression is indicative of tumorigenesis}

In order to investigate whether the increased expression of $\mathrm{R} 167 \mathrm{H}-\Delta 152 \mathrm{p} 53 \alpha$ mRNA during malignancy can be detected in serum samples and used as a biomarker, exosomes were isolated from $f T P 53^{R 167 H}$ heterozygous $(n=6)$, homozygous $(n=6)$ and wild-type $(n=3)$ pigs aged 3 and 10 months. At the age of 3 months all animals were disease free while at the age of 10 months the $f T P 53^{R 167 H}$ homozygous pigs showed first signs of cancer, confirmed later by necropsy. QPCR showed a six-fold higher level $(P<0.01)$ 
a
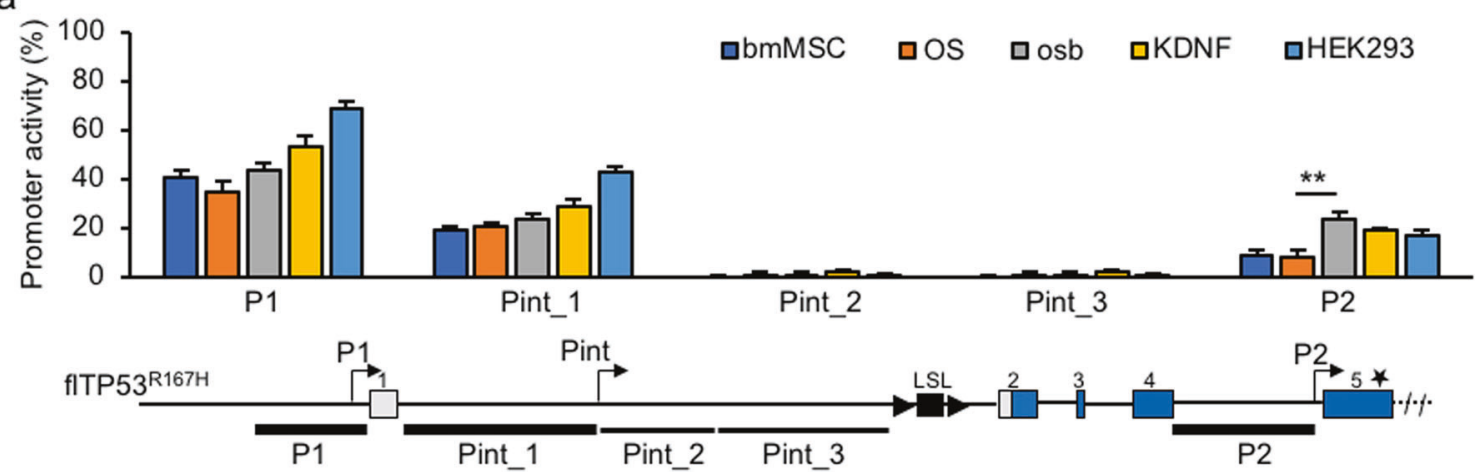

b

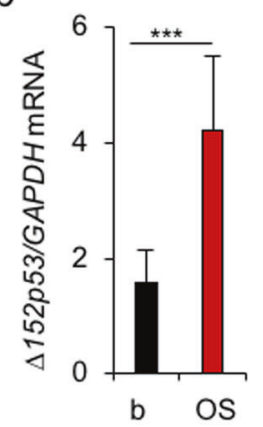

f

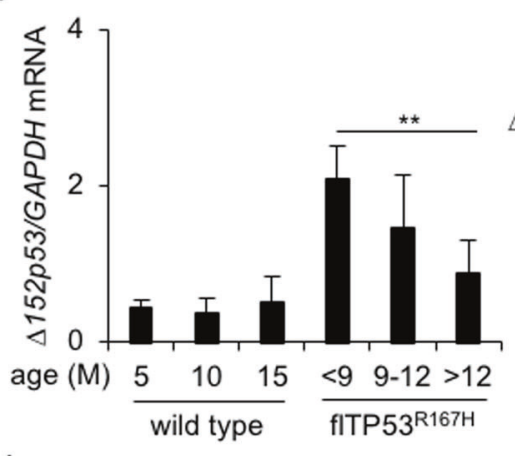

i

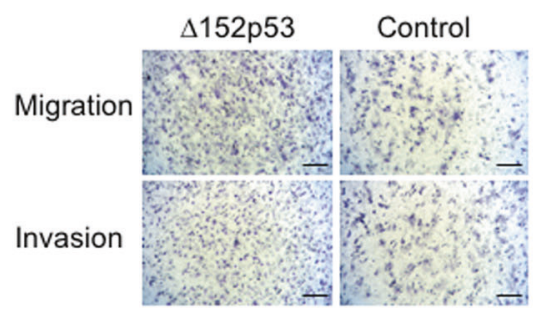

g
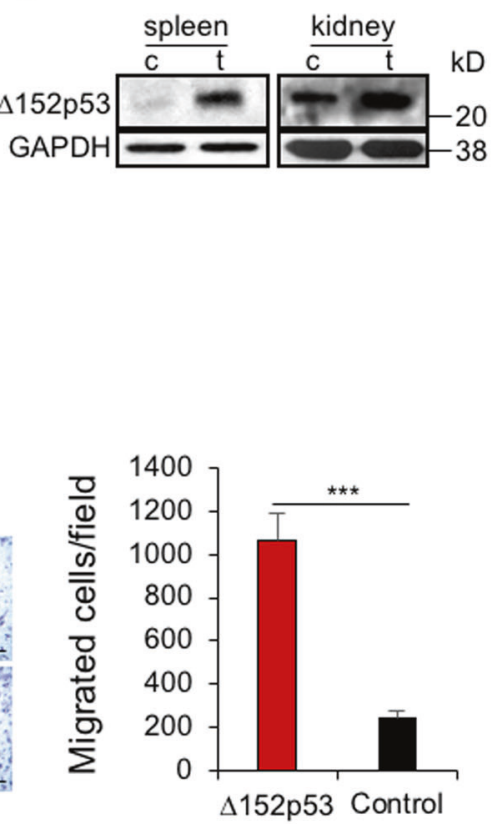

e
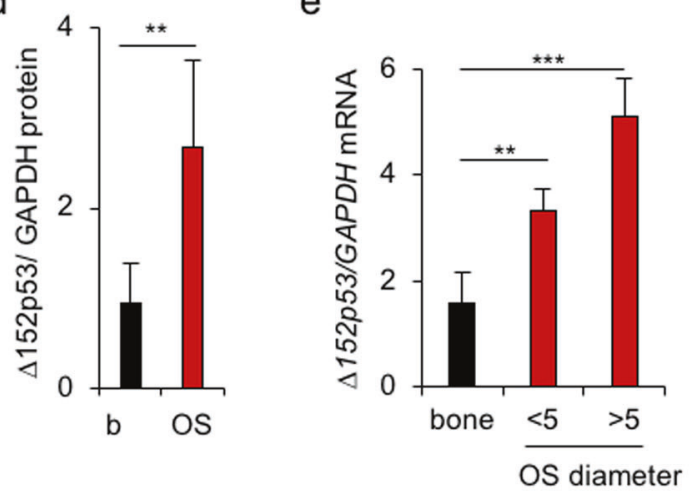

h
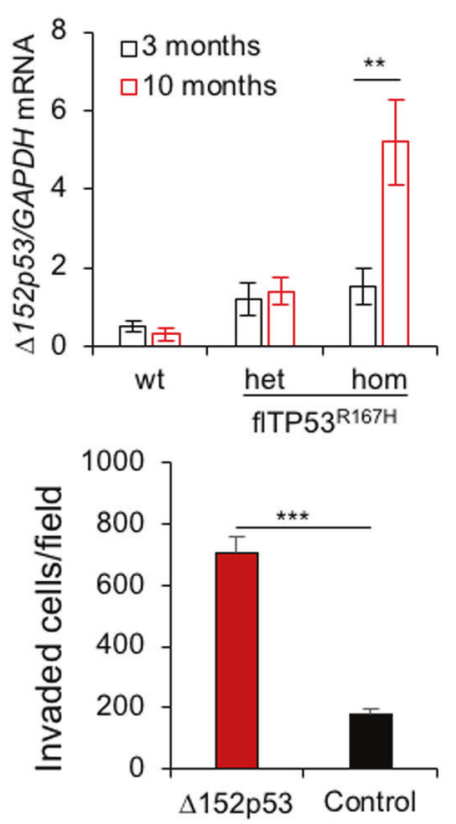

of R167H- $\Delta 152 \mathrm{p} 53 \alpha$ mRNA in exosomes from 10-month old $A T P 53^{R 167 H}$ homozygous pigs than from the same pigs at the age of 3 months (Fig. 2h). The exosomal $\Delta 152 \mathrm{p} 53$ mRNA expression in $A T P 53^{R 167 H}$ heterozygous and wildtype pigs was low and unchanged over the same time period (Fig. $2 \mathrm{~h}$ ). These data suggest that detection of $\Delta 152 \mathrm{p} 53 \alpha$ isoform mRNA in serum is indicative of tumorigenesis.
The DNA methylation in the $\mathrm{P} 2$ promoter is negatively correlated with the mutant $\Delta 152 \mathrm{p} 53 a$ expression in OS cells and tumours

The $\mathrm{P} 2$ promoter showed an increased activity in tumours. It has been reported that intragenic TP53 methylation differs between normal and transformed human colorectal cancer 
Fig. 2 Identification of porcine TP53 promoters and expression of $\Delta \mathbf{1 5 2 p 5 3 \alpha}$ isoform in osteosarcomas. a Dual-luciferase assay: luciferase was expressed from the SV40 promoter and used to normalise the Renilla expression under the control of the putative promoter fragments. Their location relative to the gene structure is depicted. Values represent mean \pm standard deviation, six transfections per construct. Promoterless luciferase vector was used as a negative control. bmMSC bone marrow mesenchymal stem cells, osb porcine flTP53 $3^{R 167 H / R 167 H}$ osteoblasts, OS porcine $f T P 53^{R 167 H / R 167 H}$ osteosarcoma cells, KDNF porcine kidney fibroblasts, HEK293 human embryonic kidney cell line. b Quantitative PCR results of $\Delta 152 \mathrm{p} 53 \alpha$ mRNA expression in OS $(n=48)$ and matched healthy bone samples. c Representative western blots showing $\Delta 152 \mathrm{p} 53 \alpha$ protein and MDM2 expression in OS and healthy matched bone samples of homozygous fITP53 ${ }^{R 167 H}$ pigs. d Quantitative measurements of proteins in OS $(n=$ $10)$ and healthy matched bone samples from homozygous $f T P 53^{R 167 H}$ pigs. e The $\Delta 152 \mathrm{p} 53 \alpha$ mRNA expression in small $(<5 \mathrm{~cm}, n=29)$ vs. large ( $>5 \mathrm{~cm}, n=19)$ tumours. f Age-dependent $\Delta 152 \mathrm{p} 53 \alpha$ mRNA expression in healthy bones of homozygous flTP5 $53^{R 167 H}(n=10)$ and wild-type $(n=3)$ pigs. $\mathrm{g}$ Western blots showing $\Delta 152 \mathrm{p} 53 \alpha$ isoform expression kidney and spleen tumours and healthy matched tissues of fTP $5^{R 167 H / R 167 H}$ pigs. h QPCR analysis of $\Delta 152 \mathrm{p} 53 \alpha$ mRNA expression in blood exosomes from flTP5 $3^{R I 67 H}$ heterozygous $(n=6)$, homozygous $(n=6)$ and wild-type $(n=3)$ pigs aged 3 and 10 months. i Migration and invasion Transwell assays for pig OS cells transfected with mutant R167H $\Delta 152$ p53 $\alpha$ isoform or a GFP control vector. Left, representative microscopic image (scale bars, $200 \mu \mathrm{m}$ ). Right, quantification of the indicated migrated and invaded cells numbers.

cell lines [34]. To evaluate if epigenetic changes correlate with altered expression levels a comparison of the DNA methylation in healthy osteoblasts and OS cells derived from $f T P P 53^{R 167 H / R 167 H}$ pigs was carried out. $\mathrm{CpG}$ regions in the P1 promoter, intron 1 (fragments Pint_1, Pint_2, Pint_3), P2 promoter and exon 5 were identified. DNA methylation at four or more $\mathrm{CpG}$ sites was analysed for each region. Overall, $\mathrm{CpG}$ methylation was higher in the gene body than in the P1 promoter (Fig. 3a), which is consistent with TP53 methylation pattern in human [35]. The highest DNA methylation $(>80 \%)$ was observed in Pint_2 and Pint_3 fragments that showed no promoter activity. The genomic regions of P1, Pint_1 and P2 promoters showed $18 \%, 28 \%$, and $64 \%$ DNA methylation in healthy osteoblasts, respectively. The DNA methylation at five CpG sites in Pint_1, P2 and exon 5 was significantly lower in OS than in healthy osteoblasts cells (Fig. 3a). The level of DNA methylation in osteoblasts and OS cells inversely correlated with promoter activity (Fig. 3b).

The same analysis was carried out for OS tissue samples. Compared to healthy bone the same five $\mathrm{CpG}$ sites as mentioned above showed significantly reduced DNA methylation in OS. The level of DNA methylation was as follows: in Pint_1-CpG3 (41\% vs. $22 \%$, healthy bone vs. OS, $P<0.01)$, in the P2 promoter- $\mathrm{CpG} 2(99 \%$ vs. $62 \%$, $P<0.0001)$ and $\mathrm{CpG} 3(96 \%$ vs. $65 \%, P<0.0001)$ site, and CpG5 (94\% vs. $63 \%, P<0.01)$ and CpG6 $(67 \%$ vs. $52 \%$, $P<0.01$ ) site within the Kozak sequence (Fig. 3c and Supplementary Fig. 6e). CpGs in this region have been shown to be differentially methylated for the $\Delta 133 / 160$ isoforms in human [34]. The regression analysis revealed that the decreased methylation at $\mathrm{CpG} 2$ and $\mathrm{CpG} 3$ sites in the P2 promoter is correlated with higher $\mathrm{R} 167 \mathrm{H}-$ $\Delta 152 \mathrm{p} 53 \alpha$ mRNA expression in OS $\left(P=2.9 \times 0^{-7}\right.$; Fig. 3d).

\section{TP53 circular RNA enhances proliferation of OS cells}

There is increasing evidence that circular RNAs (circRNAs) play a role in human cancer [36, 37], but so far no data have been reported showing expression of a circRNA for TP53 (circTP53). To identify circTP53 in $f T P 53^{R 167 H / R 167 H}$, several pairs of divergent primers were designed for RTPCR analysis resulting in the detection of four different circTP53 in flTP53 ${ }^{R I 67 H / R 167 H}$ tissues (circTP53-1 to -4, Fig. 4a), of which circTP53-3 was highly expressed in bone. All were expressed from the P2 promoter and encoded within the $\Delta 152 \mathrm{p} 53 \alpha$ isoform, which was confirmed by Sanger sequencing and RNase R digestion (Fig. 4b). RTPCR analysis revealed a tissue-specific expression of circTP53 variants, with their highest expression in bone, kidney and colon (Fig. 4c). No expression of circTP53 was found in heart and aorta, which is consistent with the lack of $\Delta 152 \mathrm{p} 53 \alpha$ expression in these organs. Compared to healthy bones, the $\operatorname{circTP53}$ expression was significantly increased $(P<0.001)$ in OS (Fig. 4d, e).

To test, whether the newly detected circTP53 has any effect on cell proliferation, an overexpression vector, consisting of exon 5 to exon 9 (circTP53-3) and the R167H mutation under the control of CMV promoter, was generated. As shown in Fig. 4f, the proliferation of pig OS cells overexpressing the circTP53 was significantly increased $(P<0.001)$ compared to cells transfected with a control GFP vector.

\section{Altered expression of $p 63$ and p73 in tumours from fITP53 ${ }^{R 167 H}$ pigs}

The p53 family includes two other members: p63 and p73, all three genes are structurally similar, and have been implicated in cell regulation and cancer $[38,39]$. This raised the question whether the TP53 mutation also influenced the expression of $\mathrm{p} 63$ and $\mathrm{p} 73$ in $\mathrm{flTP} 53^{R 167 H}$ pigs.

\section{p63}

p63 has two major isoforms, TAp63 and $\Delta$ Np63, which have different roles in tumorigenesis. While $\Delta \mathrm{Np} 63$ isoform promotes, the TAp63 suppresses tumour growth in mice [40]. Different tissues $(n=11)$ from flTP5 $3^{R 167 H}$ homozygous $(n=10)$ and wild-type $(n=3)$ pigs were analysed by qPCR with primers located in exon 3 and 
Fig. 3 DNA methylation level of porcine TP53 promoters. a DNA methylation analysis of CpGs located in putative promoter regions in TP53 in osteoblasts and OS cells of fTP $53^{R 167 H / R 167 H}$ pigs. b The correlation plot for promoter activity and DNA methylation. The values on the plot are aligned to the TP53 gene structure. c Pyrosequencing analysis of four $\mathrm{CpG}$ sites in $\mathrm{P} 2$ promoter (P2 fragment) in OS $(n=48)$ and matched healthy bone $(n=29)$ of flTP53 $3^{R 167 H}$ pigs. Values shown represent mean \pm SD. $* * P<0.01, * * * P<$ 0.001. d Regression analysis between $\mathrm{CpG}$ methylation at site 2 in $\mathrm{P} 2$ promoter and $\Delta 152 \mathrm{p} 53 \alpha$ mRNA expression in OS $(y=$ $\left.12.81-0.12, P=2.9 \times 10^{-7}\right)$. a
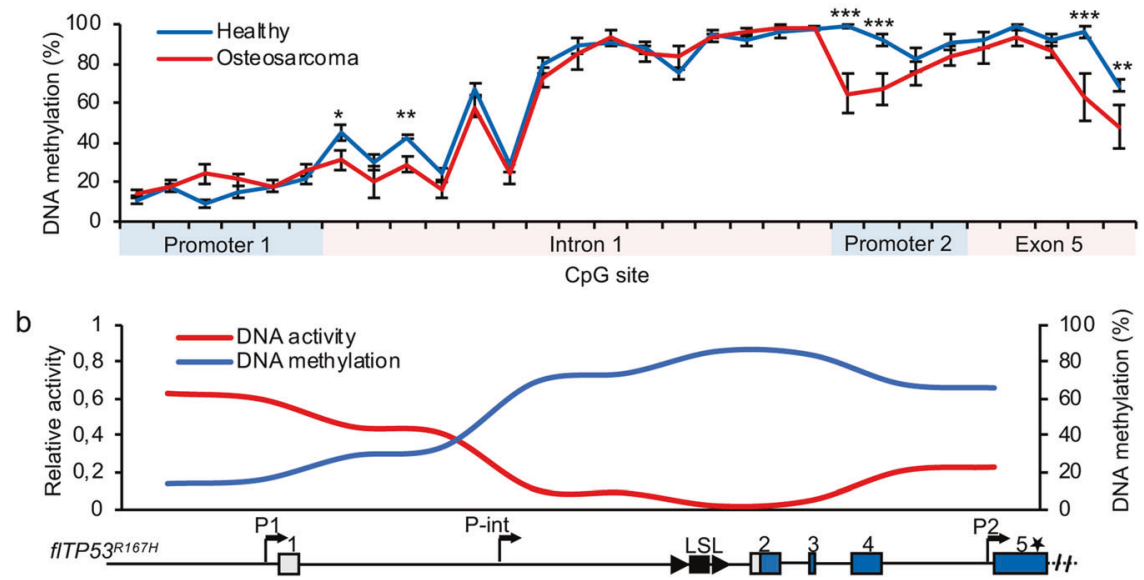

C

d

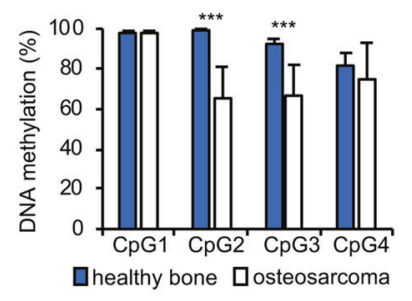

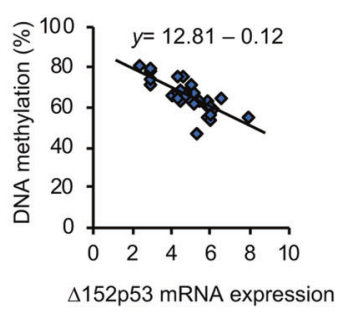

exon 4. The expression of the detected TP63 mRNA variant was significantly lower in heart, lung, bones and higher in lymph node, colon, spleen in flTP5 $3^{R 167 H}$ homozygous compared to wild-type pig tissues (Fig. 5a). Western blot analysis revealed tissue-specific expression of two TAp63 isoforms, TAp63 $\alpha$ and TAp638 and no expression of $\Delta \mathrm{Np} 63$ (Fig. $5 \mathrm{~b}$ ). While the TAp63 $\alpha$ isoform was highly expressed in wild-type kidney, the TAp638 showed an overexpression in wild-type bones, and kidney and spleen tumours (Fig. 5c), and variable expression in OS (Fig. 5d) from flTP5 $3^{R 167 H}$ pigs, indicating that the TP53 mutation has a tissue- and tumourspecific effect on the TAp638 isoform expression.

\section{p73}

In humans, $\mathrm{p} 73$ has two different promoters, which regulate several isoforms: full length TAp73 and N-terminal truncated $\Delta \mathrm{Np} 73$, which can be distinguished by their transactivation functions [41, 42]. It has been suggested that TAp73 has a tumour suppressor function similar to that of $\mathrm{p} 53$, whereas $\Delta \mathrm{Np} 73$ isoforms would promote cell growth by regulating activities of p53 family members [43]. QPCR analysis revealed a high TP73 mRNA expression in kidney, lung, liver, colon, spleen, bone, lymph node and no expression in muscle and brain of wild-type animals (Fig. 6a). It was significantly lower in colon and small intestine but higher in lung, bone, spleen of flTP53 $3^{R 167 H}$ homozygous pigs compared to wild-type (Fig. 6a). Western blot detected the TAp73 $\alpha$ isoform in kidney and liver and the TAp738 isoforms in spleen, liver, lung of flTP53 $3^{R 167 H}$ homozygous and wild-type pigs (Fig. 6b). Compared to wild-type, an overexpression of TAp73 $\delta$ isoform was observed in healthy bones (Fig. 6b) and tumours (Fig. 6c, d) from flTP53 ${ }^{R 167 H}$ homozygous pigs.

We next determined if the p73 isoforms expression is correlated with DNA methylation in the two promoter regions. A hypermethylation of the $\Delta \mathrm{Np} 73$ promoter and a hypomethylation of the TAp73 promoter was observed. The DNA methylation at all five CpG sites of TAp73 promoter differed significantly, in particular at $\mathrm{CpG} 1(21 \%$ vs. $9 \%, P<0.001$ ) between OS and matched healthy bone samples (Fig. 6f), which suggests that the CpG sites may be involved in the regulation of the TAp73 isoform expression.

To further investigate the function of $\mathrm{p} 73$ in tumorigenesis, a porcine TP73 full length cDNA expression vector, containing both the TAp73 and $\Delta \mathrm{Np} 73$ translation start codons, was transfected into porcine OS and human OS (SAOS2) cells. The TP73-transfected cells showed an overexpression of the TAp738, no expression of $\Delta \mathrm{Np} 73$ isoform (Fig. 6e) and significantly $(P<0.01)$ increased growth rate compared to the GFP transfected control cells. These data indicated that the TAp $73 \delta$ isoform is 
Fig. 4 Identification of circTP53 in $f T P 53^{R 167 H}$ pigs. a

Schematic presentation of circTP53 identification and confirmation by sanger sequencing. b Q-RT-PCR results showing the effect of RNAase R digestion. $\mathbf{c}$ RT-PCR analysis of circTP53 in different tissues in $f T P 5^{R 167 H / R 167 H}$ pigs.

d RT-PCR amplification showing the effect of RNase $R$ digestion on $\operatorname{circTP53}$ and $G A P D H$ amplification.

e Relative expression of circTP53 in healthy bones and OS. In parenthesis the number of circTP53 positive to analysed samples is shown. f Proliferation assay in pig flTP5 $3^{R 167 H / R 167 H}$ OS cells transfected with circTP53 overexpression vector, consisting of exon 5 to exon 9 (circTP53-3) under the control of CMV promoter. a
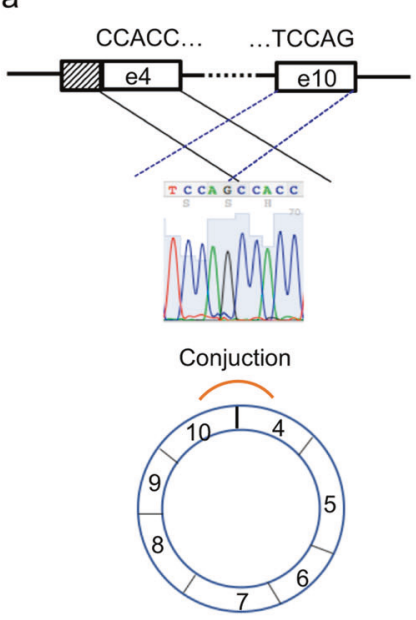

b

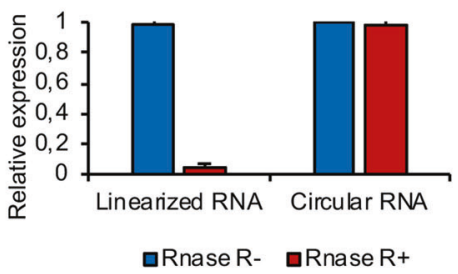

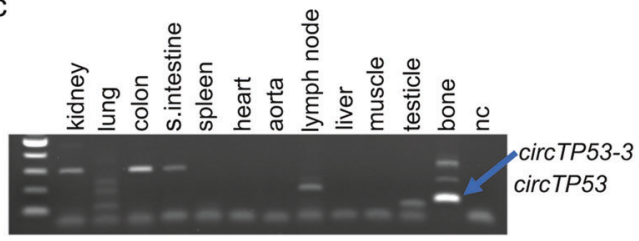

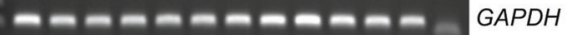
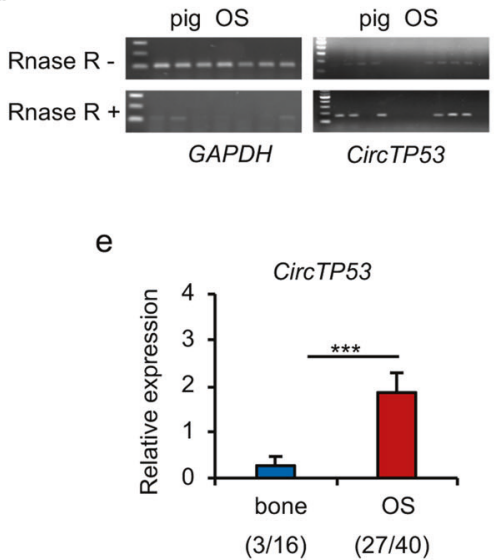

f

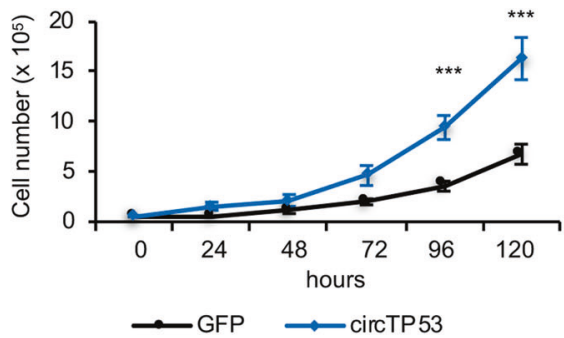

predominantly translated from the $T P 73$ cDNA and has an effect on the proliferation of these cells.

In summary, these analyses showed for the first time the expression of p63 and p73 isoforms in porcine tissues and the upregulation of the two isoforms (TAp63 and TAp73) presumed to have tumour suppressor function in porcine tumours. However, overexpression of TAp73 $\delta$ did not lead to a reduction but to an increase in cell proliferation, which may confirm that different C-terminal variants may lack growth suppressing function.

\section{Discussion}

It is becoming evident that p53 isoforms, including those derived from the internal P2 promoter, have implications in human cancers [8]. Further elucidation of their roles, interactions, regulation and patterns of expression could open novel approaches for the prognosis and treatment of cancer. But the study of p53 isoforms and its involvement in tumorigenesis had been hampered by the fact that the main experimental mammal, the mouse, lacks internal P2 promoter activity [8]. This motivated the generation of mice that ubiquitously express a $\Delta 133 \mathrm{p} 53$-like protein $(\Delta 122$ p53) through deletion of exon 3 and 4 [44, 45]. Homozygous $\Delta 122$ p53 mice show an enhanced proinflammatory phenotype and are prone to develop B-cell tumours [46] with low incidence of OS (17\%) [45]. Although this mouse model does not replicate the situation in human, its strongly supports the notion that p53 isoforms play a role in cancer.

The study presented here shows that the porcine TP53unlike the mouse-has two internal promoters, Pint in intron 1 and $\mathrm{P} 2$ in intron 4. In humans the expression from the $\mathrm{P} 2$ promoter results in two isoforms, $\Delta 160 \mathrm{p} 53$ and $\Delta 133 \mathrm{p} 53$. The porcine $\Delta 152 \mathrm{p} 53$ protein isoform is 


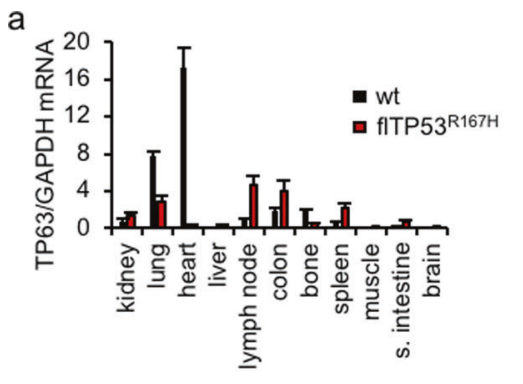

b

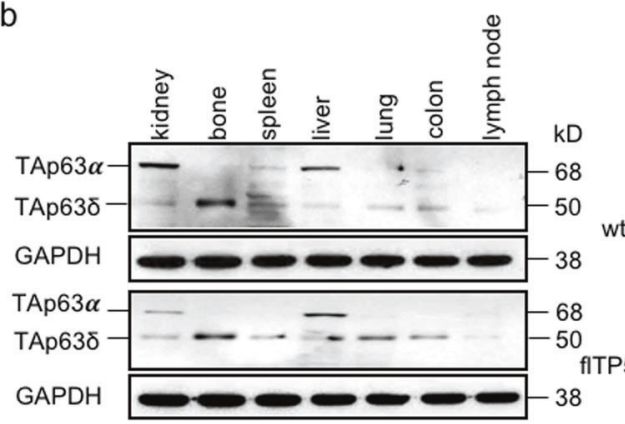

C

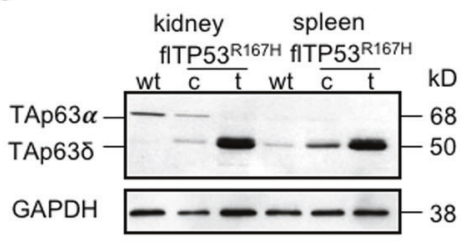

d
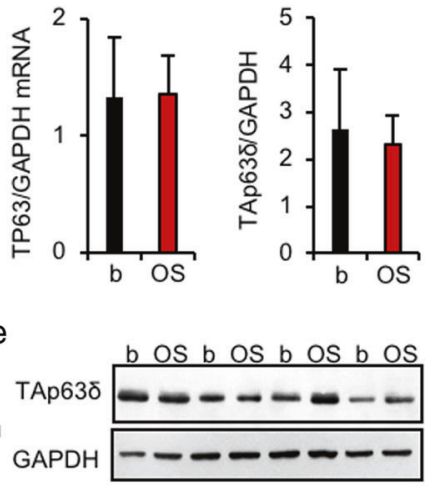

Fig. 5 Expression of p63 in $\boldsymbol{A T P} 53^{R 167 H}$ pigs. a Quantitative RT-PCR analysis of different tissues $(n=11)$ from $\operatorname{fTP} 5^{R 167 H / R 167 H}(n=6)$ and wild-type $(n=3)$ pigs. b Representative western blots showing p63 protein expression in different tissues of $f T P 5^{R 167 H / R 167 H}$ and wild-type pigs. c Western blots showing p63 isoforms expression in healthy and tumour tissues of kidney and spleen of $f T P 5^{R 167 H / R 167 H}$ and wild-type

equivalent to human $\Delta 160 \mathrm{p} 53$. The pig lacks the transcription initiation site, which in humans enables translation of the $\Delta 133 \mathrm{p} 53$ protein isoform. Three N-terminal variants have been observed in humans $(\mathrm{p} 53 \alpha, \beta, \chi)$. The porcine mRNA isolated by RT-PCR represents the $\Delta 152 \mathrm{p} 53 \alpha$ mRNA. However, western blot analysis indicated that $\mathrm{N}$-terminal variants are present in the pig.

To our best knowledge this is the first report showing an association between $\mathrm{P} 2$ promoter activity and epigenetic modifications in normal and tumour tissue. This is an important finding as epigenetic modulation has been suggested as a means of restoring wild-type p53 function, or inactivating mutant p53 activity in human cancer [47].

Comparison with human data shows that the porcine $\Delta 152 \mathrm{p} 53 \alpha \mathrm{mRNA}$ is expressed in a similar tissue-specific manner, including high expression, e.g., in bone and lack of expression in heart tissue [7]. Our study strongly suggests that the predominance of OS followed by nephroblastomas and B-cell lymphomas in pigs carrying the floxed TP53 ${ }^{R 167 H}$ allele is related to the higher level of $\Delta 152 \mathrm{p} 53 \alpha$ expression in these organs. This is further supported by the finding that pigs with early onset of OS have also higher expression of the $\Delta 152 \mathrm{p} 53 \alpha$ isoform in healthy bone tissue.

Expression of $\Delta 152 \mathrm{p} 53 \alpha$ isoform increases during tumorigenesis, which is consistent with the expression of p53 pigs. d Quantitative PCR results of p63 mRNA expression in OS $(n=$ 48 ) and matched healthy bone samples. e Representative western blots showing p63 protein expression in OS and healthy matched bone samples of homozygous $f T P 53^{R I 67 H}$ pigs. Quantitative measurements of protein in OS $(n=10)$ and matched healthy bone samples of homozygous $A T P 53^{R 167 H}$ pigs.

isoforms in human cancers [48]. The overexpression of $\Delta 133 / \Delta 160$ p53 variants and their potential oncogenic function have been reported in lung, colon, breast and ovarian cancers and in melanoma [49-52]. In the pig, an overexpression of the wild-type and mutant $\mathrm{R} 167 \mathrm{H} \Delta 152 \mathrm{p} 53 \alpha$ isoform enhanced cell proliferation, finding consistent with data for mutant $\Delta 160$ p53 isoform in human cancer cells [53]. It was more pronounced for mutant isoform, which would imply that the tissue-specific expression of the mutant $\Delta 152 \mathrm{p} 53 \alpha$ isoform drives tumorigenesis in our pig model and is an indicative blood biomarker.

$T P 53^{R 167 H}$ Yucatan minipig model generated by Sieren et al. [54] develops a similar tumour spectrum, but the role of the $\Delta 152$ p53 in this model is unknown. It is questionable if the P2 promoter is functional in this model due to the insertion of a selectable marker gene in intron 4.

It has been suggested that one of the key mechanisms for p53 gain of function mutations is its interaction with p63/ $\mathrm{p} 73[55,56]$, and that the ratio of TA/ $\Delta \mathrm{Np} 63 / \mathrm{p} 73$ isoforms determines their effect on tumorigenesis [57, 58]. We observed an upregulation of the TAp63 $\delta$ and TAp73 $\delta$ isoforms in all studied tumours, and proved that experimental overexpression of the TAp73 $\delta$ isoform increased proliferation of human and porcine OS cells. Further research is required to prove a direct interaction between the specific isoforms. 
a

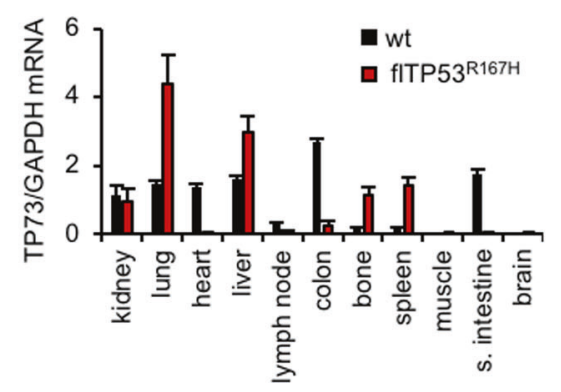

C

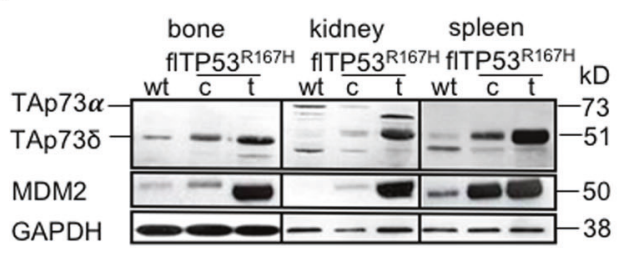

b

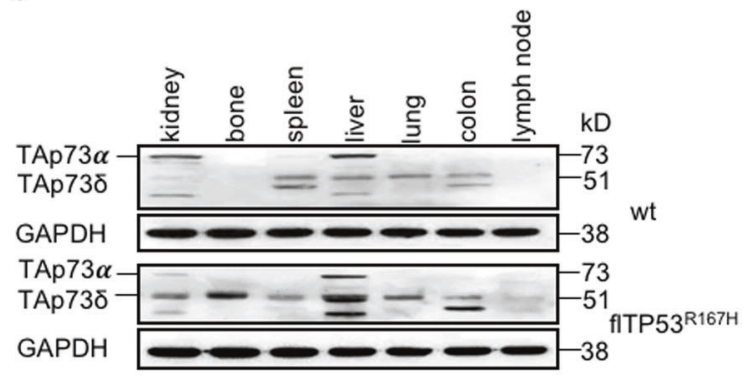

d

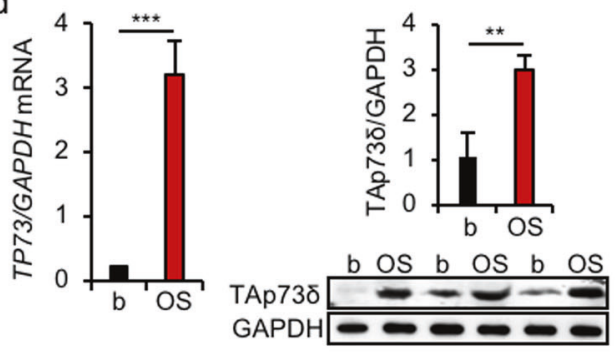

e
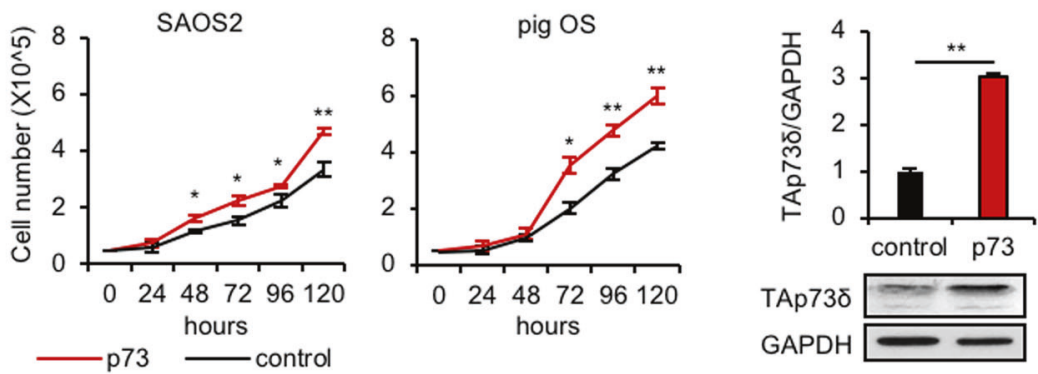

$f$
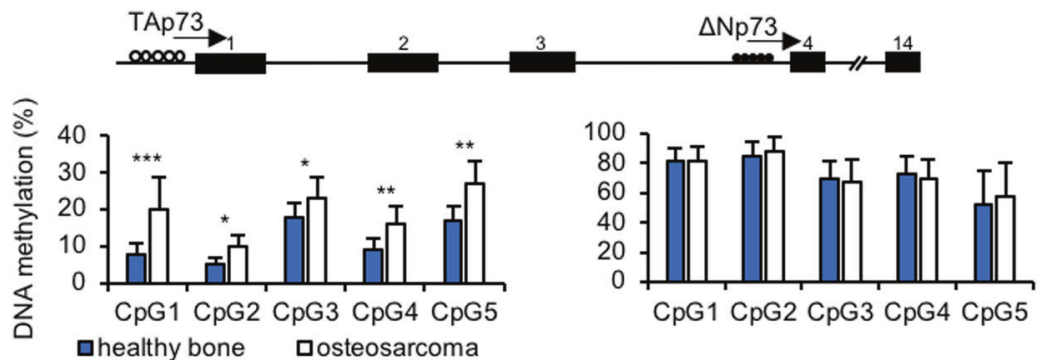

Fig. 6 Expression of p73 in $\boldsymbol{f T P} \mathbf{S 3}^{\mathrm{R} 167 \boldsymbol{H}}$ pigs. a Quantitative RT-PCR analysis of p73 mRNA expression in different tissues $(n=11)$ of fTP5 $5^{R 167 H / R 167 H}(n=6)$ and wild-type $(n=3)$ pigs. b Western blots showing the tissue-specific p73 isoforms expression in $f T P 5^{R 167 H / R 167 H}$ and wild-type pigs. $\mathbf{c}$ Western blots showing p73 isoforms and MDM2 proteins expression in bone, kidney and spleen tumours and healthy matched tissues of $A T P 5^{R 167 H / R 167 H}$ and wild-type pigs. d Quantitative PCR (left) and western blot (right) measurements showing p73 expression in OS $(n=48)$ and matched healthy bone samples. Representative western blots (bottom) showing TAp73ठ isoform expression in OS and matched healthy bone samples of homozygous

flTP53 $3^{R 167 H}$ pigs. Quantitative measurement of western blots was performed for OS $(n=10)$ and matched healthy bone $(n=10)$ samples of homozygous $f T P 53^{R I 67 H}$ pigs. e Proliferation assay in human SAOS2 (left) and pig $f T P 53^{R / 67 H / R 167 H}$ OS (middle) cells. Western blot (right) showing the upregulation of the TAp738 isoform in pig OS cells transfected with a full length of TP73 cDNA vector. The bar plot above shows the quantitative protein measurements $(n=3)$ of western blots. f DNA methylation analysis of P1 and P2 promotor regions of $T P 73$ in OS $(n=48)$ and matched healthy bone samples of fITP $53^{R 167 H}$ pigs. Open and filled circles on the TP73 gene structure indicate unmethylated and methylated DNA regions.

We present the first description of circTP53 RNAs expressed from the P2 promoter. As with the parental $\Delta 152 \mathrm{p} 53 \alpha$ isoform it is upregulated in tumours such as OS.
Importantly, the functional study demonstrated that high circTP53 expression increases cellular proliferation of OS cells. Similar mechanisms for gene overexpression and upregulation 
of circRNA was described for other genes, e.g., androgen receptor in prostate cancer [59]. The mechanism how circTP53 affects cell proliferation still needs to be elucidated.

\section{Conclusion}

The biology of p53 has been studied extensively for 4 decades and still novel insights are being gained. A crossspecies comparison might help to understand the tissuespecific regulation of TP53. Our study has highlighted the value of using the pig model. We show that the $\Delta 152 \mathrm{p} 53$ isoform, its circular counterpart and the p53 family members, TAp638 and TAp738, likely play a role in the malignant transformation of bone and other tumours. Considering the similarities of TP53 regulation between pig and human, the observations presented here provide useful information for further studies on the regulation of p53 in humans.

\section{Material and methods}

\section{Animals}

Three wild-type, ten ( 8 males and 2 females) $f T P 53^{L S L R 167 H /}$ $R 167 H$ and 24 (13 males and 11 females) $f T P 53^{L S L R 167 H /+}$ pigs aged 7-32 months were produced by normal breeding and raised in our animal husbandry facilities with food and water provided ad libitum.

\section{Necropsy examination and tumour analysis}

In total, 51 pigs were euthanised and examined by complete necropsy (without randomisation). Three bone samples from wild-type and 48 OS samples with matched healthy bones from hetero- and homozygous flTP53 $3^{L S L R 167 H}$ pigs were collected and all samples were included in the analysis. The study was non-blinded.

\section{Porcine primary cells}

Porcine bmMSC and kidney fibroblasts were derived inhouse and cultured by standard procedures [20]. All cell cultures were routinely tested for mycoplasma.

\section{Primers}

All primers used are shown in Supplementary Table S1.

For quantitative PCR, 5' and 3'RACE analysis, RNase $\mathrm{R}$ digestion, pyrosequencing, functional assays, western blot and sgRNA constructs details see Supplementary text. Unprocessed western blots are shown in Supplementary Fig. 7.

\section{Data availability}

All supporting data are included in the Supplementary file.

Acknowledgements The authors thank Johanna Tebbing for technical assistance with molecular biology, Steffen and Viola Loebnitz, Gerhard Kammermeier, Konrad Praller and Andres Sohn for animal husbandry.

Funding This work was supported by the German Research Foundation grant nos. SCHN 971/3-2, SFB 1321 and China Scholarship Council (CSC). Open Access funding enabled and organized by Projekt DEAL.

Author contributions KFlisikowski, AK, DS, J-CB and AS designed the study. GN, IH, TF, BR and AC carried out molecular experiments. $\mathrm{KF}, \mathrm{GN}$, KFischer and BK collected samples. BS, BB, EK and KS performed histopathological analysis of tumours. RB provided human OS samples. HP performed statistical analysis. KFlisikowski, TF, AK and AS wrote the manuscript with contributions from other authors. J-CB and DS edited the manuscript. All authors critically reviewed and approved the final manuscript.

\section{Compliance with ethical standards}

Conflict of interest The authors declare no competing interests.

Ethical approval All animal experiments were approved by the Government of Upper Bavaria (permit number 55.2-1-54-2532-6-13) and performed according to the German Animal Welfare Act and European Union Normative for Care and Use of Experimental Animals.

Publisher's note Springer Nature remains neutral with regard to jurisdictional claims in published maps and institutional affiliations.

Open Access This article is licensed under a Creative Commons Attribution 4.0 International License, which permits use, sharing, adaptation, distribution and reproduction in any medium or format, as long as you give appropriate credit to the original author(s) and the source, provide a link to the Creative Commons license, and indicate if changes were made. The images or other third party material in this article are included in the article's Creative Commons license, unless indicated otherwise in a credit line to the material. If material is not included in the article's Creative Commons license and your intended use is not permitted by statutory regulation or exceeds the permitted use, you will need to obtain permission directly from the copyright holder. To view a copy of this license, visit http://creativecommons. org/licenses/by/4.0/.

\section{References}

1. Mirabello L, Troisi RJ, Savage SA. International osteosarcoma incidence patterns in children and adolescents, middle ages and elderly persons. Int J Cancer. 2009;125:229-34.

2. Durfee RA, Mohammed M, Luu HH. Review of osteosarcoma and current management. Rheumatol Ther. 2016;3:221-43.

3. Bielack SS, Kempf-Bielack B, Delling G, Exner GU, Flege S, Helmke K, et al. Prognostic factors in high-grade osteosarcoma of the extremities or trunk: an analysis of 1,702 patients treated on neoadjuvant cooperative osteosarcoma study group protocols. J Clin Oncol. 2002;20:776-90. 
4. Li FP, Fraumeni JF Jr. Soft-tissue sarcomas, breast cancer, and other neoplasms. A familial syndrome? Ann Intern Med. 1969;71:747-52.

5. Ognjanovic S, Olivier M, Bergemann TL, Hainaut P. Sarcomas in TP53 germline mutation carriers: a review of the IARC TP53 database. Cancer. 2012;118:1387-96.

6. Muller PA, Vousden KH. p53 mutations in cancer. Nat Cell Biol. 2013;15:2-8.

7. Bourdon JC, Fernandes K, Murray-Zmijewski F, Liu G, Diot A, Xirodimas DP, et al. p53 isoforms can regulate p53 transcriptional activity. Genes Dev. 2005;19:2122-37.

8. Joruiz SM. p53 isoforms: key regulators of the cell fate decision. Cold Spring Harb Perspect Med. 2016;6:a026039.

9. Fujita K, Mondal AM, Horikawa I, Nguyen GH, Kumamoto K, Sohn JJ, et al. p53 isoforms Delta133p53 and p53beta are endogenous regulators of replicative cellular senescence. Nat Cell Biol. 2009;11:1135-42.

10. Bernard H, Garmy-Susini B, Ainaoui N, Van Den Berghe L, Peurichard A, Javerzat S, et al. The p53 isoform, Delta133p53alpha, stimulates angiogenesis and tumour progression. Oncogene. 2013;32:2150-60.

11. Robertson N, Schook LB, Schachtschneider KM. Porcine cancer models: potential tools to enhance cancer drug trials. Expert Opin Drug Disco. 2020;15:893-902.

12. Flisikowska T, Kind A, Schnieke A. Pigs as models of human cancers. Theriogenology. 2016;86:433-7.

13. Kalla D, Kind A, Schnieke A. Genetically engineered pigs to study cancer. Int J Mol Sci. 2020;21:488

14. Rogalla S, Flisikowski K, Gorpas D, Mayer AT, Flisikowska T, Mandella MJ, et al. Biodegradable fluorescent nanoparticles for endoscopic detection of colorectal carcinogenesis. Adv Funct Mater. 2019;29:1904992.

15. Jacks T, Remington L, Williams BO, Schmitt EM, Halachmi S, Bronson RT, et al. Tumor spectrum analysis in p53-mutant mice. Curr Biol. 1994;4:1-7.

16. Jackson JG, Lozano G. The mutant p53 mouse as a pre-clinical model. Oncogene. 2013;32:4325-30.

17. Hingorani SR, Wang L, Multani AS, Combs C, Deramaudt TB, Hruban RH, et al. Trp53R172H and KrasG12D cooperate to promote chromosomal instability and widely metastatic pancreatic ductal adenocarcinoma in mice. Cancer Cell. 2005;7:469-83.

18. Xu X, Qiao W, Linke SP, Cao L, Li WM, Furth PA, et al. Genetic interactions between tumor suppressors Brcal and p53 in apoptosis, cell cycle and tumorigenesis. Nat Genet. 2001;28:266-71.

19. Chen Z, Cheng K, Walton Z, Wang Y, Ebi H, Shimamura T, et al. A murine lung cancer co-clinical trial identifies genetic modifiers of therapeutic response. Nature. 2012;483:613-7.

20. Leuchs S, Saalfrank A, Merkl C, Flisikowska T, Edlinger M, Durkovic $\mathrm{M}$, et al. Inactivation and inducible oncogenic mutation of p53 in gene targeted pigs. PLoS ONE. 2012;7:e43323.

21. Saalfrank A, Janssen KP, Ravon M, Flisikowski K, Eser S, Steiger K, et al. A porcine model of osteosarcoma. Oncogenesis. 2016;5:e210.

22. Donehower LA, Lozano G. 20 years studying p53 functions in genetically engineered mice. Nat Rev Cancer. 2009;9:831-41.

23. Olive KP, Tuveson DA, Ruhe ZC, Yin B, Willis NA, Bronson RT, et al. Mutant p53 gain of function in two mouse models of LiFraumeni syndrome. Cell. 2004;119:847-60.

24. Lang GA, Iwakuma T, Suh YA, Liu G, Rao VA, Parant JM, et al. Gain of function of a p53 hot spot mutation in a mouse model of Li-Fraumeni syndrome. Cell. 2004;119:861-72.

25. Guijarro MV, Ghivizzani SC, Gibbs CP. Animal models in osteosarcoma. Front Oncol. 2014;4:189.

26. Seva J, Pallares FJ, Gomez MA, Bernabe A. Osteoblastic osteosarcoma in a fattening pig. Vet Rec. 2001;148:147-8.
27. Marcel V, Perrier S, Aoubala M, Ageorges S, Groves MJ, Diot A, et al. Delta160p53 is a novel N-terminal p53 isoform encoded by Delta133p53 transcript. FEBS Lett. 2010;584:4463-8.

28. Lee DS, Choung HW, Kim HJ, Gronostajski RM, Yang YI, Ryoo $\mathrm{HM}$, et al. NFI-C regulates osteoblast differentiation via control of osterix expression. Stem Cells. 2014;32:2467-79.

29. Fane M, Harris L, Smith AG, Piper M. Nuclear factor one transcription factors as epigenetic regulators in cancer. Int J Cancer. 2017;140:2634-41.

30. Denny SK, Yang D, Chuang CH, Brady JJ, Lim JS, Gruner BM, et al. Nfib promotes metastasis through a widespread increase in chromatin accessibility. Cell. 2016;166:328-42.

31. Poole LA, Cortez D. Functions of SMARCAL1, ZRANB3, and HLTF in maintaining genome stability. Crit Rev Biochem Mol Biol. 2017;52:696-714.

32. Seki M, Kimura S, Isobe T, Yoshida K, Ueno H, NakajimaTakagi Y, et al. Recurrent SPI1 (PU.1) fusions in high-risk pediatric $\mathrm{T}$ cell acute lymphoblastic leukemia. Nat Genet. 2017;49:1274-81.

33. Peng Y, Chen L, Li C, Lu W, Agrawal S, Chen J. Stabilization of the MDM2 oncoprotein by mutant p53. J Biol Chem. 2001;276:6874-8.

34. Blackburn J, Roden DL, Ng R, Wu J, Bosman A, Epstein RJ. Damage-inducible intragenic demethylation of the human TP53 tumor suppressor gene is associated with transcription from an alternative intronic promoter. Mol Carcinog. 2016;55:1940-51.

35. Tornaletti S, Pfeifer GP. Complete and tissue-independent methylation of $\mathrm{CpG}$ sites in the p53 gene: implications for mutations in human cancers. Oncogene. 1995;10:1493-9.

36. Zhang J, Liu H, Hou L, Wang G, Zhang R, Huang Y, et al. Circular RNA_LARP4 inhibits cell proliferation and invasion of gastric cancer by sponging miR-424-5p and regulating LATS1 expression. Mol Cancer. 2017;16:151.

37. Chen N, Zhao G, Yan X, Lv Z, Yin H, Zhang S, et al. A novel FLI1 exonic circular RNA promotes metastasis in breast cancer by coordinately regulating TET1 and DNMT1. Genome Biol. 2018;19:218.

38. Chen S, Moroi Y, Urabe K, Takeuchi S, Kido M, Hayashida S, et al. Differential expression of two new members of the p53 family, p63 and p73, in extramammary Paget's disease. Clin Exp Dermatol. 2008;33:634-40.

39. Jost CA, Marin MC, Kaelin WG Jr. p73 is a simian [correction of human] p53-related protein that can induce apoptosis. Nature. 1997;389:191-4.

40. Flores ER, Sengupta S, Miller JB, Newman JJ, Bronson R, Crowley D, et al. Tumor predisposition in mice mutant for $\mathrm{p} 63$ and p73: evidence for broader tumor suppressor functions for the p53 family. Cancer Cell. 2005;7:363-73.

41. Irwin MS. DeltaNp73: misunderstood protein? Cancer Biol Ther. 2006;5:804-7.

42. Conforti F, Yang AL, Agostini M, Rufini A, Tucci P, NicklisonChirou MV, et al. Relative expression of TAp73 and DeltaNp73 isoforms. Aging (Albany NY). 2012;4:202-5.

43. Moll UM. The role of p63 and p73 in tumor formation and progression: coming of age toward clinical usefulness. Commentary re: F. Koga et al., Impaired p63 expression associates with poor prognosis and uroplakin III expression in invasive urothelial carcinoma of the bladder. Clin. Cancer Res. 2003;9:5501-7, and P. Puig et al., p73 Expression in human normal and tumor tissues: loss of p73alpha expression is associated with tumor progression in bladder Cancer. Clin. Cancer Res. 2003;9:5642-51. Clin Cancer Res. 2003;9:5437-41.

44. Slatter TL, Hung N, Bowie S, Campbell H, Rubio C, Speidel D, et al. Delta122p53, a mouse model of Delta133p53alpha, enhances the tumor-suppressor activities of an attenuated p53 mutant. Cell Death Dis. 2015;6:e1783. 
45. Slatter TL, Hung N, Campbell H, Rubio C, Mehta R, Renshaw P, et al. Hyperproliferation, cancer, and inflammation in mice expressing a Delta133p53-like isoform. Blood. 2011;117:5166-77.

46. Campbell HG, Slatter TL, Jeffs A, Mehta R, Rubio C, Baird M, et al. Does Delta133p53 isoform trigger inflammation and autoimmunity? Cell Cycle. 2012;11:446-50.

47. Bykov VJN, Eriksson SE, Bianchi J, Wiman KG. Targeting mutant p53 for efficient cancer therapy. Nat Rev Cancer. 2018;18:89-102.

48. Anbarasan T, Bourdon JC. The emerging landscape of p53 isoforms in physiology, cancer and degenerative diseases. Int $\mathrm{J}$ Mol Sci. 2019;20:6257.

49. Fragou A, Tzimagiorgis G, Karageorgopoulos C, Barbetakis N, Lazopoulos A, Papaioannou M, et al. Increased Delta133p53 mRNA in lung carcinoma corresponds with reduction of p21 expression. Mol Med Rep. 2017;15:1455-60.

50. Hofstetter G, Berger A, Schuster E, Wolf A, Hager G, Vergote $\mathrm{I}$, et al. Delta133p53 is an independent prognostic marker in p53 mutant advanced serous ovarian cancer. Br J Cancer. 2011;105:1593-9.

51. Nutthasirikul N, Limpaiboon $T$, Leelayuwat C, Patrakitkomjorn S, Jearanaikoon P. Ratio disruption of the 133 p53 and TAp53 isoform equilibrium correlates with poor clinical outcome in intrahepatic cholangiocarcinoma. Int $\mathrm{J}$ Oncol. $2013 ; 42: 1181-8$.
52. Avery-Kiejda KA, Morten B, Wong-Brown MW, Mathe A, Scott RJ. The relative mRNA expression of p53 isoforms in breast cancer is associated with clinical features and outcome. Carcinogenesis. 2014;35:586-96.

53. Candeias MM, Hagiwara M, Matsuda M. Cancer-specific mutations in p53 induce the translation of Delta160p53 promoting tumorigenesis. EMBO Rep. 2016;17:1542-51.

54. Sieren JC, Meyerholz DK, Wang XJ, Davis BT, Newell JD Jr., Hammond E, et al. Development and translational imaging of a TP53 porcine tumorigenesis model. J Clin Invest. 2014;124:4052-66.

55. Stindt MH, Muller PA, Ludwig RL, Kehrloesser S, Dotsch V, Vousden KH. Functional interplay between MDM2, p63/p73 and mutant p53. Oncogene. 2015;34:4300-10.

56. Zhang J, Sun W, Kong X, Zhang Y, Yang HJ, Ren C, et al. Mutant p53 antagonizes p63/p73-mediated tumor suppression via Notch1. Proc Natl Acad Sci USA. 2019;116:24259-67.

57. Gonfloni S, Caputo V, Iannizzotto V. P63 in health and cancer. Int J Dev Biol. 2015;59:87-93.

58. Lucena-Araujo AR, Kim HT, Thome C, Jacomo RH, Melo RA, Bittencourt R, et al. High DeltaNp73/TAp73 ratio is associated with poor prognosis in acute promyelocytic leukemia. Blood. 2015;126:2302-6.

59. Robinson D, Van Allen EM, Wu YM, Schultz N, Lonigro RJ, Mosquera JM, et al. Integrative clinical genomics of advanced prostate cancer. Cell. 2015;161:1215-28. 